\title{
A reduction of perfusion can lead to an artificial elevation of slow diffusion measure: examples in acute brain ischemia MRI intravoxel incoherent motion studies
}

\author{
Yì Xiáng J. Wáng^ \\ Department of Imaging and Interventional Radiology, Faculty of Medicine, The Chinese University of Hong Kong, New Territories, Hong Kong, \\ China \\ Correspondence to: Dr. Yì Xiáng J. Wáng. Department of Imaging and Interventional Radiology, Faculty of Medicine, The Chinese University of \\ Hong Kong, New Territories, Hong Kong, China. Email: yixiang_wang@cuhk.edu.hk.
}

Submitted Mar 26, 2021. Accepted for publication May 07, 2021.

doi: 10.21037/atm-21-1468

View this article at: http://dx.doi.org/10.21037/atm-21-1468

Intravoxel incoherent motion (IVIM) theory in magnetic resonance imaging (MRI) was proposed by Le Bihan et al. to account for the effect of vessel/capillary perfusion on the aggregate diffusion weighted MR signal. The fast component of diffusion is related to micro-perfusion, whereas the slow component is linked to water molecular diffusion. Three parameters can be computed. $\mathrm{D}_{\text {slow }}$ (or $D$ ) is the diffusion coefficient representing the slow "pure" water molecular diffusion (unaffected by perfusion). The perfusion fraction (PF, or $f$ ) represents the fraction of the compartment related to (micro)circulation, which can be understood as the proportional "incoherently flowing fluid" (i.e., blood) volume. $\mathrm{D}_{\text {fast }}$ (or $D^{*}$ ) is the perfusionrelated diffusion coefficient representing the incoherent microcirculation within the voxel, which holds information for blood perfusion's speed. Among IVIM research community, it has been generally assumed that the perfusion component and the diffusion component can be separately determined. We recently reported that, for the liver, IVIM modeling of the perfusion component is constrained by the diffusion component, and a reduced $\mathrm{D}_{\text {slow }}$ measure leads to artificially higher $\mathrm{PF}$ and $\mathrm{D}_{\text {fast }}$ measures $(1,2)$. Two related questions would then follow: Is this phenomenon also observed in organs other than the liver? Can a reduction of PF lead to an artificial elevation of $\mathrm{D}_{\text {slow }}$ measure? We argue that the answer is "yes" to both questions. Hereby, we explain this point by using examples in existing brain IVIM literatures with acute PF change being the initiating factor. These examples suggest a lower PF can lead to a higher observed $\mathrm{D}_{\text {slow. }}$.

By increasing arterial carbon dioxide pressure $\left(\mathrm{PaCO}_{2}\right)$, McKinstry et al. (3) induced brain grey matter perfusion increases in three dogs and IVIM imaging of the brain was acquired. $\mathrm{PaCO}_{2}$ was changed according to the order of: low $\mathrm{PaCO}_{2}$, high $\mathrm{PaCO}_{2}$, and normal $\mathrm{PaCO}_{2}$. Their IVIM analysis in Fig-5 shows, among various $\mathrm{PaCO}_{2}$, $\mathrm{PF}$ and $\mathrm{D}_{\text {slow }}$ changed toward the opposition directions. When PF went up, $\mathrm{D}_{\text {slow }}$ went down; when PF went down, $\mathrm{D}_{\text {slow }}$ went up. Pavilla et al. (4) studied cerebral hypoperfusion induced by hyperventilation challenge in 10 healthy volunteers. For the IVIM measures, they reported cerebellum grey matter had PF of $0.16 \pm 0.07$ under normal ventilation and $0.07 \pm 0.09(\mathrm{P}=0.03)$ under hyperventilation, while $D_{\text {slow }}$ was $0.55 \pm 0.10$ and $0.63 \pm 0.13\left(\times 10^{-3} \mathrm{~mm}^{2} / \mathrm{s}\right.$, $\mathrm{P}=0.05)$ respectively under normal ventilation and hyperventilation. Thus, hyperventilation included lower PF and higher $\mathrm{D}_{\text {slow }}$ measures in cerebellum grey matter. In the study by $\mathrm{Xu}$ et al. (5), a middle cerebral artery occlusion model was established in 24 beagle dogs, and IVIM imaging data were acquired at 4.5 hours after model establishment. Serum soluble CD40L level was used as an indicator of microvascular thrombosis after acute ischemic stroke onset, with its higher level associated with more microvascular thrombosis events

$\wedge$ ORCID: 0000-0001-5697-0717. 
and thus lower perfusion in the ischemic stroke lesions $(5,6)$. Their Fig-5A (for $\mathrm{D}_{\text {slow }}$ ) and Fig-5B (for PF) show a potential negative correlation between $\mathrm{PF}$ and $\mathrm{D}_{\text {slow }}$. Compared with the contralateral healthy brain hemisphere $\left[\mathrm{PF}=0.055 \pm 0.008, \mathrm{D}_{\text {slow }}=(0.813 \pm 0.152) \times 10^{-3} \mathrm{~mm}^{2} / \mathrm{s}\right]$, the stroke lesions had lower PF and low $\mathrm{D}_{\text {slow: }}$. However, the stroke lesions with higher serum soluble CD40L level and lower PF $(0.041 \pm 0.007)$ had higher $\mathrm{D}_{\text {slow }}(0.531 \pm 0.153)$ than $\mathrm{D}_{\text {slow }}(0.435 \pm 0.044, \mathrm{P}=0.057)$ of the stroke lesions with lower serum soluble CD40L level and higher PF $(0.051 \pm 0.007$, $\mathrm{P}<0.001)$. With IVIM measures of 20 acute ischemic stroke patients, Zhu et al. (7) reported penumbra zone, ipsilateral non-ischemia region, and contralateral healthy hemisphere had PF of $0.0541 \pm 0.0323,0.0755 \pm 0.0454$, and $0.0722 \pm 0.0293$ respectively, while the corresponding $\mathrm{D}_{\text {slow }}$ measure was $0.847 \pm 0.116,0.819 \pm 0.225,0.842 \pm 0.100$ $\left(\times 10^{-3} \mathrm{~mm}^{2} / \mathrm{s}\right)$ respectively, with the lowest $\mathrm{PF}$ associated with highest $\mathrm{D}_{\text {slow }}$ and highest $\mathrm{PF}$ associated with lowest $\mathrm{D}_{\text {slow }}$.

In interpreting the relationship between $\mathrm{PF}$ and $\mathrm{D}_{\text {slow, }}$ it should be noted that acute brain ischemia (with a reduction of PF) can indeed induce cytotoxic edema resulting in a reduction of $\mathrm{D}_{\text {slow }}(8,9)$. When both $\mathrm{PF}$ and $\mathrm{D}_{\text {slow }}$ are truly decreased and the decrease of $D_{\text {slow }}$ is of sufficient extent, $D_{\text {slow }}$ can be measured as "decreased" [such as the case for IVIM measure of brain ischemic core (7-9)]; though a possibility remains that, even for such decreased $D_{\text {slow }}$ measures, their observed value is still over-estimated. On the other hand, there likely is a PF change magnitude window which does not induce observed $\mathrm{D}_{\text {slow }}$ reduction but instead induce observed $\mathrm{D}_{\text {slow }}$ artificial elevation. As time goes on, ischemia induced cytotoxic edema may turn into vasogenic edema which will demonstrate a true $\mathrm{D}_{\text {slow }}$ elevation $(8,9)$. In the examples of McKinstry et al. (3), Pavilla et al. (4) and $\mathrm{Xu}$ et al. (5), brain changes or lesions would not have had dominant vasogenic edema with overall true $\mathrm{D}_{\text {slow }}$ elevation. In the example of $\mathrm{Zhu}$ et al. (7), for the retrospective cohort of stroke patients with vessel occlusion, the mean time from onset to treatment was $8.3 \pm 5.1$ hours and MRI was conducted before the treatment, it is still more likely that there was no sufficient vasogenic edema leading to overall true $\mathrm{D}_{\text {slow }}$ elevation.

The point discussed here will have important implications in interpreting IVIM data. For example, in the report by Zhu et al. (7), the penumbra zone had a decreased PF of $0.0541 \pm 0.0323$ (normal: $0.0722 \pm 0.0293$, ischemic core: $0.0445 \pm 0.0262$ ), while the observed $\mathrm{D}_{\text {slow }}$ was $(0.847 \pm 0.116) \times 10^{-3} \mathrm{~mm}^{2} / \mathrm{s}$ [normal:
$(0.842 \pm 0.100) \times 10^{-3} \mathrm{~mm}^{2} / \mathrm{s}$, ischemic core: $\left.(0.544 \pm 0.111) \times 10^{-3} \mathrm{~mm}^{2} / \mathrm{s}\right]$. Considering the degree of $\mathrm{PF}$ reduction, there could be a possibility that penumbra zone's true $\mathrm{D}_{\text {slow }}$ had decreased, the observed $\mathrm{D}_{\text {slow }}$ which was normal (or slightly higher than normal) was masked by an artificial increase of $D_{\text {slow }}$ measure due to true reduction of PF. Moreover, the results of McKinstry et al. (3) and Zhu et al. (7) also suggest the possibility that a truly increased PF can lead to an artificial lowering of $\mathrm{D}_{\text {slow }}$ measure. In the study of McKinstry et al. (3), when a PF increase was induced by increasing $\mathrm{PaCO}_{2}$, a lowering of $\mathrm{D}_{\text {slow }}$ was noted. In the results of Zhu et al. (7), compared with the contralateral healthy brain, the ipsilateral non-ischemia region had slightly higher PF measure $(0.0755 \pm 0.0454)$ than that of the contralateral brain (PF: $0.0722 \pm 0.0293$ ) which would have been caused by collateral blood flow compensation (10), resulting in a slightly lower $\mathrm{D}_{\text {slow }}$ measure than that of the contralateral brain $(0.819 \pm 0.225 \mathrm{vs}$. $0.842 \pm 0.100 \times 10^{-3} \mathrm{~mm}^{2} / \mathrm{s}$ ).

Taking together the evidence explained here and our previously discussions $(1,2)$, it can be summarized that, if one component, being perfusion component or diffusion component, changes toward one direction (i.e., increase or decrease), the other component will be constrained to change toward the opposite direction to a certain extent. For this problem, one might expect the cause could be that currently prevalent IVIM modeling does not fully consider the varied noise proportions of diffusion weighted images scanned under different acquisition conditions (11). However, our preliminary further analysis showed noise correction only slightly improved this "constraining". Moreover, the prevalent IVIM modeling is based on Eq. [1]:

$$
\mathrm{SI}_{(\mathrm{b})} / \mathrm{SI}_{(0)}=(1-\mathrm{PF}) \times \exp \left(-b \times \mathrm{D}_{\text {slow }}\right)+\mathrm{PF} \times \exp \left(-b \times \mathrm{D}_{\text {fast }}\right)
$$

where $\mathrm{SI}_{(\mathrm{b})}$ and $\mathrm{SI}_{(0)}$ denote the signal intensity of images acquired with the $b$-factor value of $b$ and $b=0 \mathrm{~s} / \mathrm{mm}^{2}$, respectively. With higher $b$-value associated lower image signal of the target tissue, Eq. [1] is focused on describing the signal decay pattern along increasingly higher $b$-values by three IVIM parameters $\left(\mathrm{PF}, \mathrm{D}_{\text {slow }}, \mathrm{D}_{\text {fast }}\right)$. Signal intensity at each $b$-value [i.e., $\mathrm{SI}_{(\mathrm{b})}$ ] is normalised by the signal intensity of $b=0$ image [i.e., $\left.\mathrm{SI}_{(0)}\right]$. Applying this approach, for example if we want to compare the IVIM parameters of the normal brain and a brain tumor, we will take $\mathrm{SI}_{(0)}$ of the normal brain and $\mathrm{SI}_{(0)}$ of the tumor both as 1 (or 100) for the biexponential decay modelling, thus we would be assuming the $\mathrm{SI}_{(0)}$ of the normal brain and the $\mathrm{SI}_{(0)}$ the 
tumor are equal. This could be invalid in many scenarios. We demonstrated that an initial lower $\mathrm{SI}_{(0)}$ of the target tissue is associated with a lower $\mathrm{D}_{\text {slow }}$ and a higher PF $(1,2,11,12)$, regardless of whether we used segmented fitting or full fitting (1). Regardless of whatever methods we use to fit the curve of the diffusion weighted imaging signal decay along increasingly higher $b$-values, IVIM parameters are determined by this curve's pattern which is in turn determined by relativity of $\mathrm{SI}_{(\mathrm{b})}$ to $\mathrm{SI}_{(0)}$. Therefore, target tissues of different compositions, which have different $\mathrm{SI}_{(0)}$, may not necessarily be directly compared with the three IVIM parameters. For example, if two living tissues had the same diffusion and perfusion as well as other biological properties but these two tissues had different iron contents, we would expect the tissue with higher iron content would have lower $\mathrm{SI}_{(0)}$, lower measured $\mathrm{D}_{\text {slow, }}$ and higher measured $\mathrm{PF}$ (12). We consider this problem is not easily solvable by a better fitting approach, by high signal-to-noise images, or by an extensive array of $b$-value images. Further research to better separate diffusion component and perfusion component should be pursued $(1,13)$. Another possible approach would be that, if the reference values of IVIM diffusion and perfusion components are already known with standardised data acquisition, then we may be able to understand how these constrains can be computationally compensated for each target tissue.

\section{Acknowledgments}

The author thanks Mr. Ben-Heng Xiao, at the Chinese University of Hong Kong, Hong Kong, for helpful discussions.

Funding: None.

\section{Footnote}

Provenance and Peer Review: This article was a standard submission to the journal. The article has undergone external peer review.

Conflicts of Interest: The author has completed the ICMJE uniform disclosure form (available at http://dx.doi. org/10.21037/atm-21-1468). The author has no conflicts of interest to declare.

Ethical Statement: The author is accountable for all aspects of the work in ensuring that questions related to the accuracy or integrity of any part of the work are appropriately investigated and resolved.

Open Access Statement: This is an Open Access article distributed in accordance with the Creative Commons Attribution-NonCommercial-NoDerivs 4.0 International License (CC BY-NC-ND 4.0), which permits the noncommercial replication and distribution of the article with the strict proviso that no changes or edits are made and the original work is properly cited (including links to both the formal publication through the relevant DOI and the license). See: https://creativecommons.org/licenses/by-nc-nd/4.0/.

\section{References}

1. Huang H, Zheng CJ, Wang LF, et al. Age and gender dependence of liver diffusion parameters and the possibility that intravoxel incoherent motion modeling of the perfusion component is constrained by the diffusion component. NMR Biomed 2021;34:e4449.

2. Wáng YXJ. Observed paradoxical perfusion fraction elevation in steatotic liver: An example of intravoxel incoherent motion modeling of the perfusion component constrained by the diffusion component. NMR Biomed 2021;34:e4488.

3. McKinstry RC, Weiskoff RM, Belliveau JW, et al. Ultrafast MR imaging of water mobility: animal models of altered cerebral perfusion. J Magn Reson Imaging 1992;2:377-84.

4. Pavilla A, Arrigo A, Mejdoubi M, et al. Measuring Cerebral Hypoperfusion Induced by Hyperventilation Challenge With Intravoxel Incoherent Motion Magnetic Resonance Imaging in Healthy Volunteers. J Comput Assist Tomogr 2018;42:85-91.

5. Xu XQ, Wu CJ, Lu SS, et al. Correlation between Intravoxel Incoherent Motion Magnetic Resonance Imaging Derived Metrics and Serum Soluble CD40 Ligand Level in an Embolic Canine Stroke Model. Korean J Radiol 2017;18:835-43.

6. Ishikawa M, Vowinkel T, Stokes KY, et al. CD40/CD40 ligand signaling in mouse cerebral microvasculature after focal ischemia/reperfusion. Circulation 2005;111:1690-6.

7. Zhu G, Federau C, Wintermark M, et al. Comparison of MRI IVIM and MR perfusion imaging in acute ischemic stroke due to large vessel occlusion. Int J Stroke 2020;15:332-42.

8. Li TQ, Chen ZG, Hindmarsh T. Diffusion-weighted MR imaging of acute cerebral ischemia. Acta Radiol 1998;39:460-73.

9. Schaefer PW, Grant PE, Gonzalez RG. Diffusion- 


\section{Page 4 of 4}

weighted MR imaging of the brain. Radiology 2000;217:331-45.

10. Copen WA, Schaefer PW, Wu O. MR perfusion imaging in acute ischemic stroke. Neuroimaging Clin N Am 2011;21:259-83, x.

11. Wáng YXJ. Mutual constraining of slow component and fast component measures: some observations in liver IVIM imaging. Quant Imaging Med Surg 2021;11:2879-87.

12. Xiao BH, Wáng YXJ. Different tissue types display

Cite this article as: Wáng YXJ. A reduction of perfusion can lead to an artificial elevation of slow diffusion measure: examples in acute brain ischemia MRI intravoxel incoherent motion studies. Ann Transl Med 2021;9(10):895. doi: 10.21037/ atm-21-1468

\section{Wáng. Perfusion reduction leads to artificial $D_{\text {slow }}$ elevation}

different signal intensities on $b=0$ images and the implications of this for intravoxel incoherent motion analysis: Examples from liver MRI. NMR Biomed 2021;e4522.

13. Xiao BH, Huang H, Wang LF, et al. Diffusion MRI Derived per Area Vessel Density as a Surrogate Biomarker for Detecting Viral Hepatitis B-Induced Liver Fibrosis: A Proof-of-Concept Study. SLAS Technol 2020;25:474-83. 